\title{
PKMS CABE MERAH UNGGUL DI JORONG JOPANG NAGARI JOPANG MANGANTI KECAMATAN MUNGKA KABUPATEN LIMA PULUH KOTA SUMATERA BARAT
}

\author{
Helti Andraini ${ }^{1}$, Dara Surtina ${ }^{2}$, Harissatria ${ }^{3}$, Renfiyeni ${ }^{4}$, Friza Elinda ${ }^{5}$, John Hendri ${ }^{6}$, \\ Mahmud $^{7}$, Mardianto $^{8}$ \\ 1,4,5) Jurusan Agroteknologi, Fakultas Pertanian Universitas Mahaputra Muhammad Yamin \\ ${ }^{2,3,6)}$ Program Studi Peternakan, Fakultas Pertanian Universitas Mahaputra Muhammad Yamin \\ ${ }^{7,8)}$ Jurusan Agribisnis, Fakultas Pertanian Universitas Mahaputra Muhammad Yamin \\ email: heltiandraini@gmail.com
}

\begin{abstract}
Abstrak
Usaha tani cabai merah yang ada pada kelompok tani Gonjong Merah yang berada di Nagari Jopang manganti Kecamatan Mungka merupakan kelompok tani cabe merah keriting semenjak tahun 2012. Permasalahan yang ada pada kelompok tani mira adalah 1 . Kurangnya sosialisasi dan pelatihan dan edukasi yang didapat dari instansi terkait tentang sistem budidaya cabai merah. 2. Petani cabai merah tidak pernah mengukur $\mathrm{pH}$ dari tanah saat penanaman. Setiap petani terus menanan cabai merah di lahan secara berulang-ulang tanpa mempertimbangkan kondisi tingkat keasaman dari tanah. 3 . Tidak pernah menerapakan teknologi mulsa plastik. 4. Petani mitra ini tidak tahu bagaimana teknik dan cara pemupukan yang baik pada tanaman cabai. 5. Permasalahan lain yang dirasakan oleh mitra ini adalah sulitnya mendapatkan bibit cabai merah yang baik dan unggul. Metode kegiatan adalah dalam bentuk pelatihan dan pembinaan yang dilakukan selama delapan bulan. Hasil dari kegiatan adalah menyediakan bibit unggul cabe merah keriting varitas kencana, obat-obatan, fungisida, desinfektam, perbaikan pemupukan, mulsa plastik dan $\mathrm{pH}$ meter.
\end{abstract}

Kata Kunci : Cabai Merah, Bibit Unggul, Kompos

\begin{abstract}
The red chili farming in the Gonjong Merah farmer group in Nagari Jopang manganti, Mungka District has been a curly red chili farmer group since 2012. The problems that exist in the mira farmer group are 1. Lack of socialization and training and education obtained from related agencies regarding red chili cultivation system. 2. Red chilli farmers never measure the $\mathrm{pH}$ of the soil during planting. Each farmer continues to plant red chilies in the land repeatedly without considering the acidity level of the soil. 3. Never applied plastic mulch technology. 4. These partner farmers do not know how to properly fertilize chili plants. 5. Another problem felt by these partners was the difficulty of getting good and superior red chili seeds. The method of activity is in the form of training and coaching which is carried out for eight months. The result of the activity is to provide superior seeds of red chilli with golden varieties, medicines, fungicides, disinfectants, improved fertilization, plastic mulch and $\mathrm{pH}$ meters.
\end{abstract}

Keywords: Red Chilies, Superior Seeds, Compost

\section{PENDAHULUAN}

Cabai merah (Capsicum Annuum L.) merupakan tanaman hortikultura yang banyak dimanfaatkan untuk kebutuhan pangan. Menurut Rukmana dan Oesman (2006), pemanfaatannya dalam industri menjadikan cabai sebagai komoditas bernilai ekonomi tinggi. Kebutuhan akan cabai merah, masih dapat ditingkatkan dengan pesat sejalan dengan kenaikan pendapatan dan atau jumlah penduduk sebagaimana terlihat dari trend permintaan yang cenderung meningkat yaitu tahun 1992 mencapai sebesar 3,16 kg/kapita, pada tahun 2002 mencapai 4,19kg/kg/kapita (Santika, 2002 dan Soetrisno 2010). Salah satu upaya untuk meningkatkan produksi tanaman cabai dengan cara mengolah lahan secara tepat agar kesuburan tanah tetap terjaga (Dermawaan, 2010). Pemupukan merupakan salah satu tindakan pemeliharaan tanaman yang utama untuk mendapatkan pertumbuhan yang optimal. Dalam rangka memacu produksi tanaman cabai merah ada beberapa faktor yang dapat dilakukan disamping 
pengguanaan benih dan bibit unggul yaitu manipulasi lingkungan seperti pemberian mulsa pada bedengan tempat tumbuh (Umboh, 2002). Keberhasilan usahatani cabai merah, selain ditentukan oleh kemampuan SDM/Petani untuk melaksanakan budidaya khususnya dalam mengantisipasi dan mengatasi masalah hama/penyakit tanaman, juga ditentukan oleh dukungan teknologi mulai dari pemilihan varietas, pengolahan lahan dan tananam yang tepat serta pemupukan yang efisien (Prajnanta, 2007).

Usaha tani cabai merah yang ada pada kelompok mitra Gonjong Merah yang berada di Nagari Jopang Manganti Kecamatan Mungka Kabupaten Lima Puluh Kota merupakan kelompok tani yang sudah lama menjalankan usahatani cabai merah semenjak tahun 2012. Anggota petani yang tergabung dalam usaha tani ini kebanyakan bapak-bapak yang rata-rata sudah hampir berumur 50 tahun sebanyak 6 orang dan perempuan 2 orang. Tingkat pendidikan petenai bawang ini rata-rata tamatan SLTP. Setiap anggota kelompok tani ini pada umumnya memiliki luas lahan tanaman cabai merah tidak lebih dari 200 meter per segi dan tergolong kepada usaha kecil menengah yang berpotensi bisa berkembang jika diberikan sentuhan teknologi budidaya yang tepat. Selama ini setip anggota kelompok tani ini melakukan usaha ini masih bersifat tradisional dan belum adanya sentuhan teknologi budidaya yang baik. Sebagai salah satu contoh tidak andanya pemakaian mulsa plastik pada bedengan tanaman cabai yang ditanam oleh mitra sehingga gulma dan rumput liar akan banyak tumbuh disekitar tanaman cabai sehingga memakan unsur hara yang diperlukan oleh tanaman cabai merah.

Petani cabai merah di kelompok mitra Gonjong Merah umumnya mendapatkan benih dari tanaman cabai merah yang telah dibudidayakan sebelumnya secara turun temurun, hal ini menyebabkan kualitas benih tidak murni lagi yang bisa berpengaruh pada keragaman tumbuh, produktifitas dan kerentanan terhadap gangguan hama dan penyakit. Kualitas benih atau galur cabai masih terlihat sebagai kendala yang menyebabkan rendahnya produksi. Selaian itu salah satu kendala utama dalam budidaya tanaman cabai adalah gangguan penyakit layu Fusarium yang disebabkan oleh jamur Fusarium oxysporum f.sp.capsici (Foca) (Rostini, 2011). Jamur patogen ini dapat menyerang tanaman cabai merah mulai dari masa perkecambahan sampai dewasa. Adanya serangan Foca menjadi salah satu pembatas yang menyebabkan terjadinya penurunan produksi cabai. Kerugian akibat penyakit layu fusarium pada tanaman cabai cukup besar. Selain itu permasalahn yang lain adalah para petani cabai merah tidak pernah mengukur $\mathrm{pH}$ dari tanah saat penanaman cabai merah. Setiap petani terus menanan cabai merah di lahan secara berulang-ulang tanpa mempertimbangkan kondisi tingkat keasaman dari tanah. Seperti diketahui Jenis tanah yang paling baik untuk budidaya cabai merah adalah tanah lempung berpasir atau lempung berdebu (Naniratih, et, al., 2013). Selanjutnya petani di kelompok mitra selama ini menanam cabai merah tidak pernah menerapakan teknologi mulsa plastik. Akibat dari hal tersebut, tanaman lain seperti rumput liar mudah tumbuh di sekeliling tanaman cabai yang mana dapat mengganggu pertumbuhan bcabai merah karena bersaing untuk mendapatkan makanan. Permasalah lain adalah petani dikelompok mitra ini tidak tahu bagaimana teknik dan cara pemupukan yang baik pada tanaman cabai merah. Selama ini petenai di kelompok mitra ini hanya memberikan pupuk kimia secara terus menerus seperti pupuk urea dan pupuk NPK. Akibat dari pemakaian pupuk kimia secara terus menerus mengakibatkan kandungan unsure hara yang ada dalam tanah menjadi berkurang dan tingkat kegemburan menjadi rendah. Hal ini mengakibtkan produktivitas dari tanaman bawang menjadi rendah. Selanjutnya para petani tidak tidak pernah melakukan usaha untuk meningkatakan kesuburan tanah menggunkan pupuk kandang atau kompos, yang mana pemakaian pupuk kandang dan kompos bisa meningkatkan kandungan unsure hara dan penggemburan tanah. Selain tidak pernah melakukan pemupukan dengan kompos, para petani juga tidak paham seberapa banyak dosis yang tepat dalam pemberian pupuk kandang atau kompos sesuai dengan luas lahan. Selanjutnya drainase yang buruk juga menjadi faktor pemburuk dari kegiatan usaha tani bcabai merah yang dilakukan oleh mitra. Selanjutnya untuk mengurangi tingkat keasaman dari tanah petani mitra juga tidak sanggup untuk membeli kapur atau dolomite sehingga lahan yang ditanam cabai merah tidak bisa tumbuh secara maksimum.

\section{METODE}

Untuk merealisasikan program ini maka upaya yang dilaksanakan ada 6 tahap mulai dari persiapan sampai tahap pelaksanaan program dapat dilihat pada bagan berikut ini : 


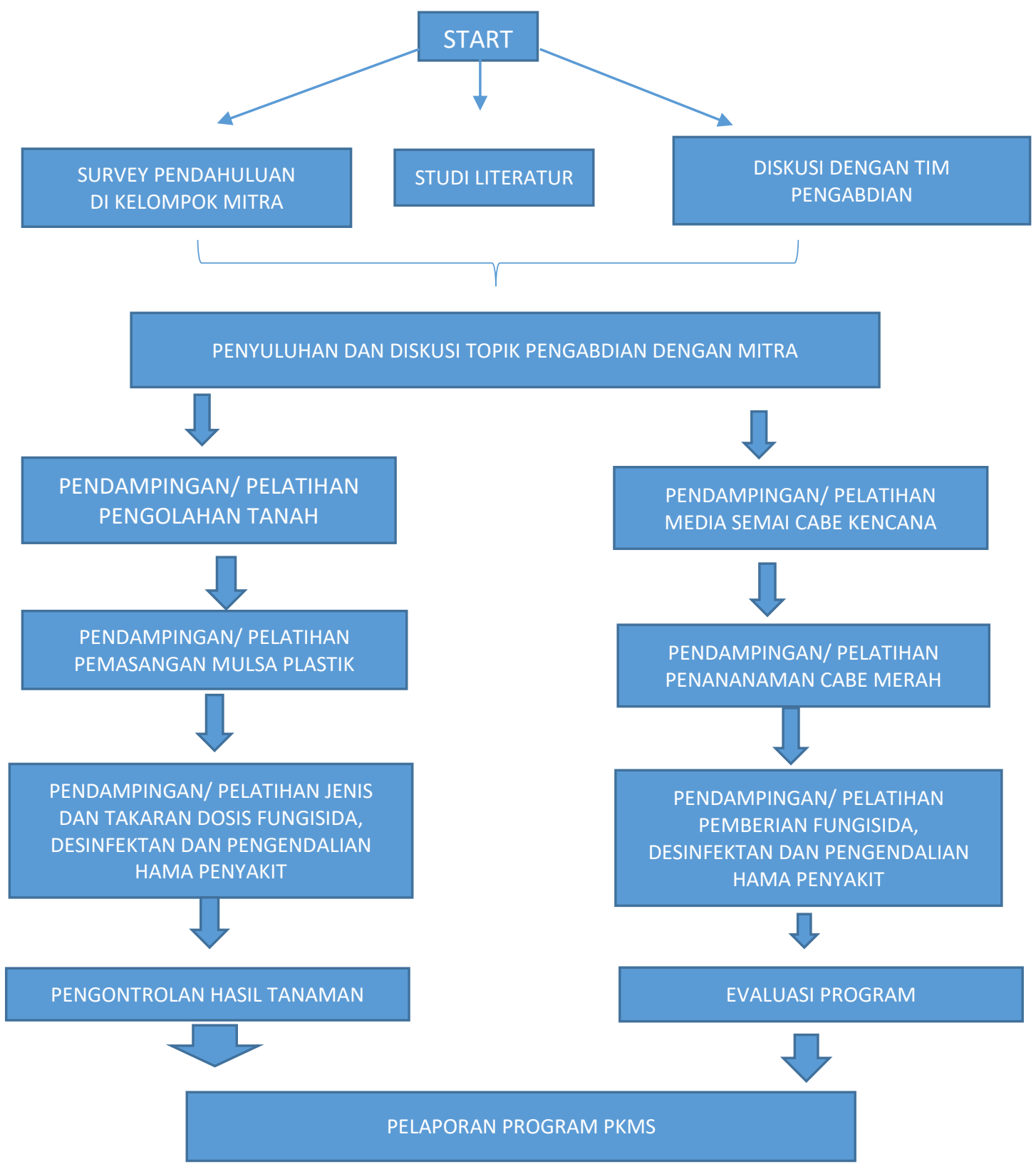

\section{BAGAN 1. METODE PELAKSANAAN PKMS}

1. Melakukan survei lapangan. Survei ini dilakukan untuk mendapatkan data yang relevan dengan kegiatan PKMS ini. Adapun data dikumpulkan melalui wawancara dan observasi lapangan.

2. Study Literatur yaitu: mencari literatur yang relevan dengan masalah yang dihadapi budidaya cabe merah keriting dan solusi atas permasalahan secara teoritis dalam aspek produksi dan manajemen usaha.

3. Melakukan diskusi sesama tim pengabdian untuk memecahkan permasalahan mitra.

4. Penyuluhan dan diskusi dengan mitra:
a. Penyuluhan pengolahan tanah
b. Penyuluhan pemupukan tanah
c. Penyuluhan dosis pemupukan kimia dan kompos
d. Penyuluhan pemakaian dolomit dan pengukuran $\mathrm{pH}$ tanah
e. Penyuluhan pemakaian bibit unggul
f. Penyuluhan penyemaian bibit dalam tray
g. Penyuluhan pengendalian hama penyakit 
h. Penyuluhan jenis fungisida, desinfektan serta obat-obatan cabe merah

5. Pendampingan dan praktek langsung kelapangan tentang materi yang diberikan saat penyuluhan dan diskusi

6. Evaluasi program menggunkan kuisioner dan daftar pertanyaan

7. Pelaporan kegiatan PKMS

\section{HASIL DAN PEMBAHASAN}

Berdasarkan dari kegiatan pengabdian masyarakat yang dilaskukan semenjak bulan Maret tahun 2020 sampai bulan oktober 2020 Maka dampak ekonomi dan sosial yang didapatkan oleh petani mitra adalah dapat disajikan dalam Tabel 1 berikut ini :

Tabel 1. Manfaat kegiatan PKMS 2020

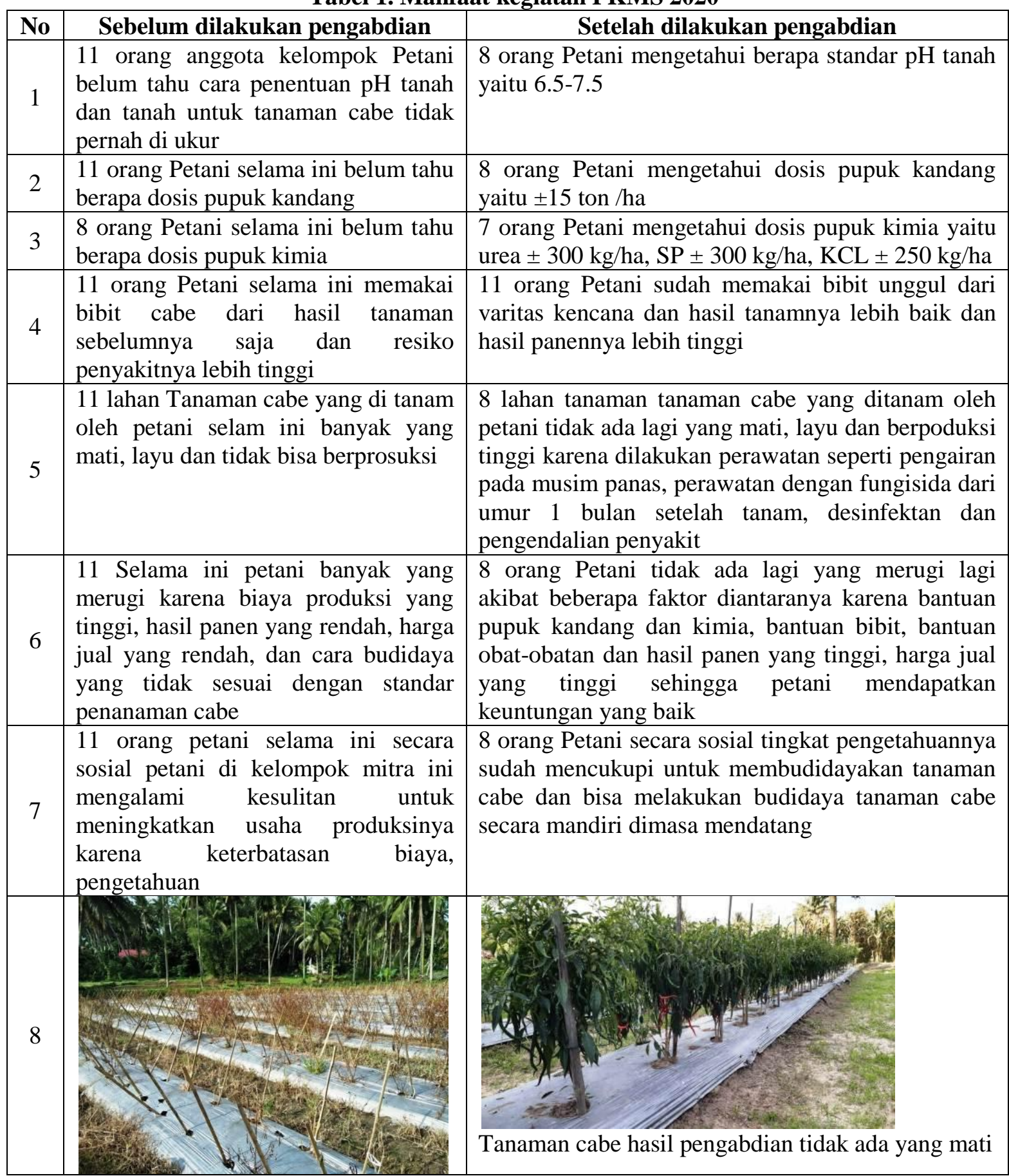




\begin{tabular}{|c|l|l|}
\hline & $\begin{array}{l}\text { Tanaman cabe sebelum pengabdian } \\
\text { banyak yang mati }\end{array}$ & \\
\hline \multirow{5}{*}{9} & $\begin{array}{l}11 \text { orang petani Rata-rata bisa } \\
\text { memproduksi cebe selama panen } \pm \\
300-400 \mathrm{~kg} / 2000 \text { batang per orang } \\
\text { tanaman cabe per lahan }\end{array}$ & $\begin{array}{l}\text { 6 orang petani sudah bisa memproduksi cabe 1.100 } \\
\text { kg per orang per lahan dan 3 orang petani baru bisa } \\
\text { memproduksi 650 kg per orang per lahan dari 2000 } \\
\text { batang tanaman cabe /lahan }\end{array}$ \\
\hline \multirow{5}{1}{10} & $\begin{array}{l}11 \text { orang petani rata-rata mendapatkan } \\
\text { keuntungan selama ini dari 2000 } \\
\text { batang tanaman cabe Rp. 1.500.000 - } \\
\text { 2.500.000 per orang per lahan }\end{array}$ & Rp. 7.600.000 - 8.900.000,- \\
\hline
\end{tabular}

\section{Manfaat Mitra terhadap Pelaksanaan}

Dalam kegiatan pengabdian yang dilakukan, ada beberapa manfaat kepada anggota kelompok mitra ini diantaranya :

\section{Kontribusi Kelompok Tani dalam Tukar Menukar Pikiran}

Kontribusi kelompok dalam kelas belajar dapat dilihat melalui peran kelompok dalam tukar menukar pikiran. Dengan saling tukar menukar pikiran baik anggota maupun pengurus dapat membantu kegiatan organisasi. Untuk peran kelompok dapat dilihat pada Tabel 2.

Tabel 2. Kontribusi Kelompok Tani dalam Tukar Menukar Pikiran

\begin{tabular}{|l|c|c|c|c|c|}
\hline No & Alternatif Jawaban & Skor & Jumlah Responden & $\mathbf{\%}$ & Total skor \\
\hline 1 & Selalu & 3 & 11 & 73 & 33 \\
\hline 2 & Kadang-kadang & 2 & 3 & 20 & 6 \\
\hline 3 & Tidak pernah & 1 & 1 & 7 & 1 \\
\hline \multicolumn{2}{|c|}{ Total } & 15 & 100 & 40 \\
\hline
\end{tabular}

Hasil kegiatan ini menunjukkan bahwa 73\% (11 orang) dengan menjawab selalu berdiskusi hal ini karena anggota melakukan perannya dalam tukar menukar pikiran dalam upaya pengembangan tanaman cabe. Hal ini dilakukan agar supaya kelompok dapat dengan mudah mengatasi masalahmasalah yang terjadi. Dengan saling tukar pikiran dapat melaksanakan tujuan bersama. Sedangkan, $20 \%$ (3 orang ) menjawab kadang-kadang karena anggota tidak selalu hadir dalam setiap pertemuan yang dilakukan oleh ketua Kelompok tani. Anggota Kelompok tani tidak pernah melakukan tukar menukar pikiran sebesar 7\% (1 orang) karena mempunyai pekerjaan yang lain sehingga dia tidak dapat menghadiri pertemuan. Anggota yang berada dalam kelompok tani saling tukar-menukar informasi, dan dengan adanya kelancaran arus informasi semakin tinggi kepuasan anggota, berarti dinamika kelompok semakin baik. Biasanya anggota kelompok saling menjelaskan sesuatu kepada anggota apabila ada hal-hal yang kurang jelas seperti anggota yang lebih berpengalaman akan menjelaskan kepada anggota yang lain yang belum mengetahuinya. Biasanya informasi tentang kegiatan pemberantasan atau pengendalian hama dan penyakit secara terpadu, berusaha memperbaiki prasarana-prasarana yang menunjang usaha taninya.

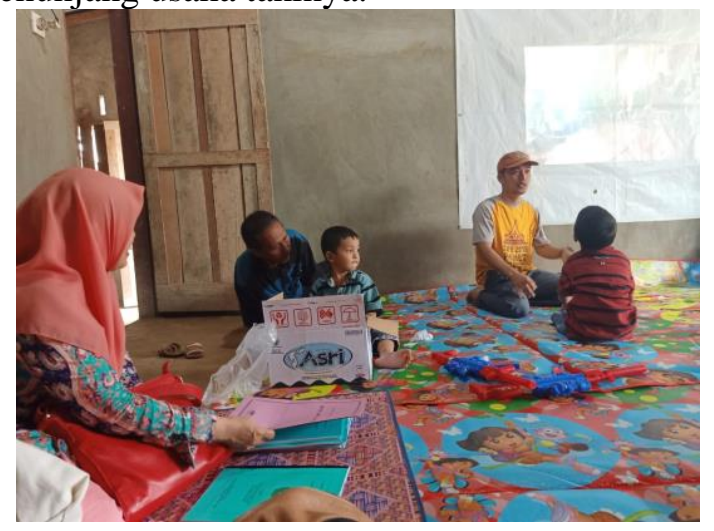

Gambar 1. Diskusi dengan Para petani Cabai 


\section{Kontribusi petani dalam mengatasi hama penyakit}

Tabel 3. Kontribusi petani dalam mengatasi hama penyakit

\begin{tabular}{|l|c|c|c|c|c|}
\hline No & Alternatif Jawaban & Skor & Jumlah Responden & \% & Total skor \\
\hline 1 & Selalu & 3 & 10 & 67 & 30 \\
\hline 2 & Kadang-kadang & 2 & 1 & 26 & 8 \\
\hline 3 & Tidak pernah & 1 & 4 & 7 & 1 \\
\hline \multicolumn{2}{|c|}{ Total } & 15 & 100 & 39 \\
\hline
\end{tabular}

Hasil kegiatan menunjukkan bahwa 67\% kelompok melakukan kerjasama dalam mengatasi masalah yang terjadi pada penanggulangan hama dan penyakit pada tanaman cabe karena dengan bersama-sama akan lebih mudah anggota mengatasi masalah yang terjadi. Sedangkan, $26 \%$ menjawab masih jarang atau kadang-kadang melakukan kerjasama karena anggota kelompok lain hanya berharap pada Pendamping dalam mengatasi masalah pada tanaman cabe. $7 \%$ yang tidak pernah melakukan kerjasama karena anggota sudah mempercayakan penuh kepada tim kegiatan pengabdian ini. Dalam penanggulangan hama dan penyakit tanaman cabe ini biasanya petani di kelompok ini melaksanakan pengadaan bibit yang resisten untuk memenuhi kepentingan para anggotanya termasuk pengadaan sarana produksi murah dengan cara melakukan pembelian secara bersama-sama pula.

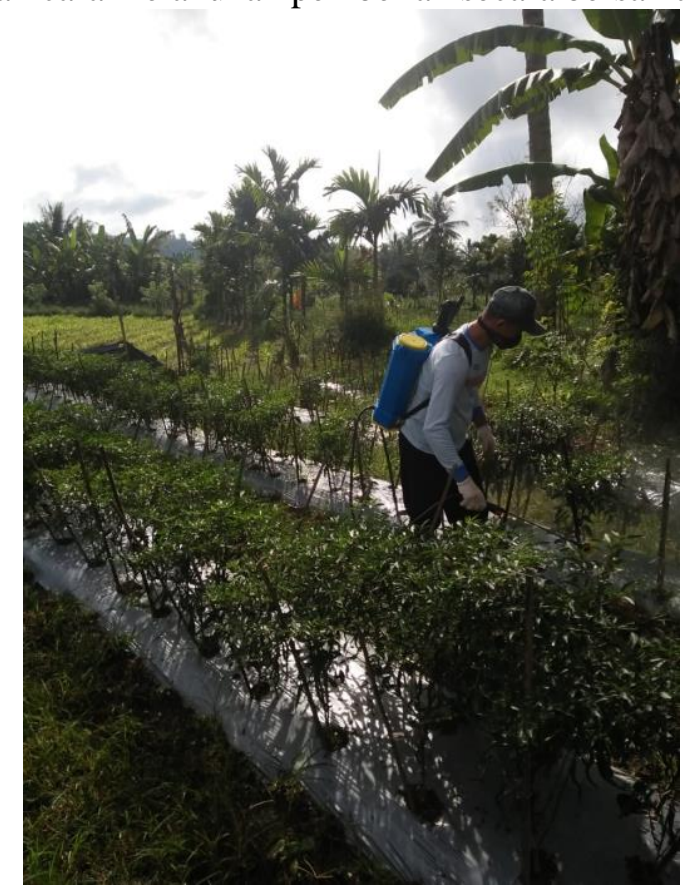

Gambar 2. Petani sedang melakukan penyemprotan pada tanaman cabe

\section{Kontribusi dalam Melakukan Pertemuan Berkala}

Dari pernyataan ini dilihat apakah Kelompok tani melakukan pertemuan berkala untuk membahas pengembangan tanaman cabe terkait dengan teknologi maupun sarana produksi.

Tabel 4. Kontribusi dalam melakukan pertemuan berkala

\begin{tabular}{|l|c|c|c|c|c|}
\hline No & Alternatif Jawaban & Skor & Jumlah Responden & $\mathbf{\%}$ & Total skor \\
\hline 1 & Selalu & 3 & 7 & 47 & 21 \\
\hline 2 & Kadang-kadang & 2 & 8 & 53 & 16 \\
\hline 3 & Tidak pernah & 1 & 0 & 0 & 0 \\
\hline \multicolumn{2}{|c|}{ Total } & 15 & 100 & 37 \\
\hline
\end{tabular}

Dari hasil kegiatan menunjukkan bahwa 47\% (7orang) kelompok melakukan pertemuan berkala untuk membahas pengembangan tanaman cabe alasannya karena dengan melakukan pertemuan 
berkala akan lebih mudah dan akan semakin berkembang organisasinya baik Teknologi maupun sarana produksi pada kelompok tani. Sedangkan, yang jarang atau kadang-kadang melakukan pertemuan sebanyak 53\% alasan anggota mereka hadir apabila mereka tidak ada kegiatan lain atau ada aktivitas lain.

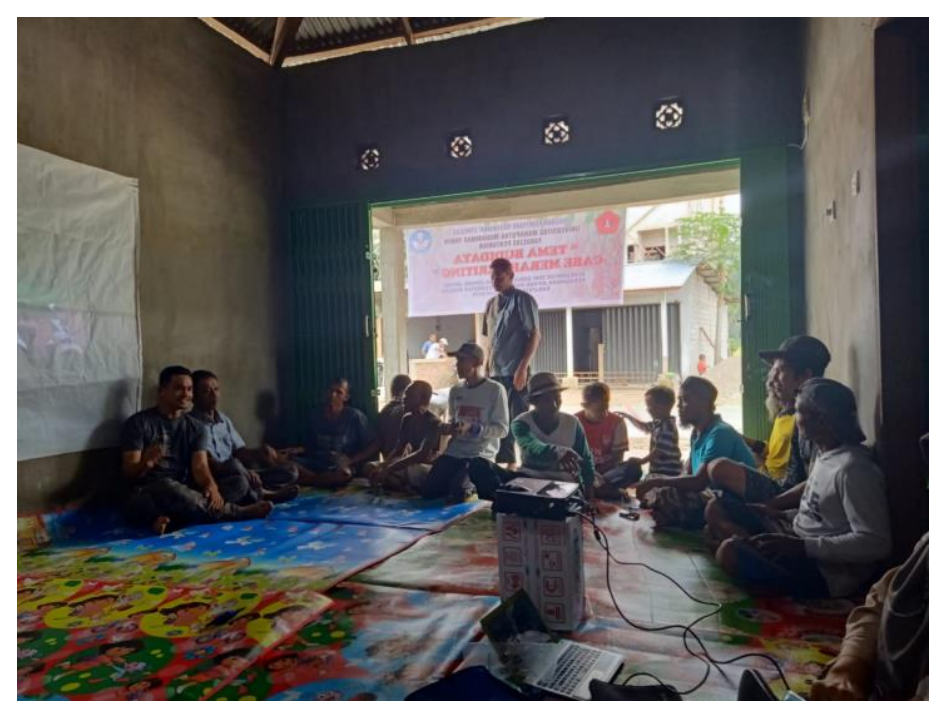

Gambar 3. Diskusi dengan Para Petani Cabe

\section{Kontribusi Melaksanakan Survei Identifikasi Kebutuhan Pasar}

Tabel 5. Kontribusi Melaksanakan Survei Identifikasi Kebutuhan Pasar

\begin{tabular}{|l|c|c|c|c|c|}
\hline No & Alternatif Jawaban & Skor & Jumlah Responden & \% & Total skor \\
\hline 1 & Selalu & 3 & 6 & 40 & 18 \\
\hline 2 & Kadang-kadang & 2 & 6 & 40 & 12 \\
\hline 3 & Tidak pernah & 1 & 3 & 20 & 3 \\
\hline \multicolumn{2}{|c|}{ Total } & 15 & 100 & 33 \\
\hline
\end{tabular}

Dari kegiatan ini menunjukkan bahwa petani yang menjawab selalu dan jarang melakukan kegiatan seperti melaksanakan survei identifikasi kebutuhan pasar memiliki persentase yang sama yaitu $40 \%$ karena dengan dilakukannya Survei identifikasi maka petani dengan mudah mengetahui harga naik turunnya tanaman cabe. Anggota kelompok tidak pernah melaksanakan hanya $20 \%$ karena mereka langsung menjual kepada Tengkulak dan berapa pun harga yang ditentukan Tengkulak mereka tetap menjualnya.

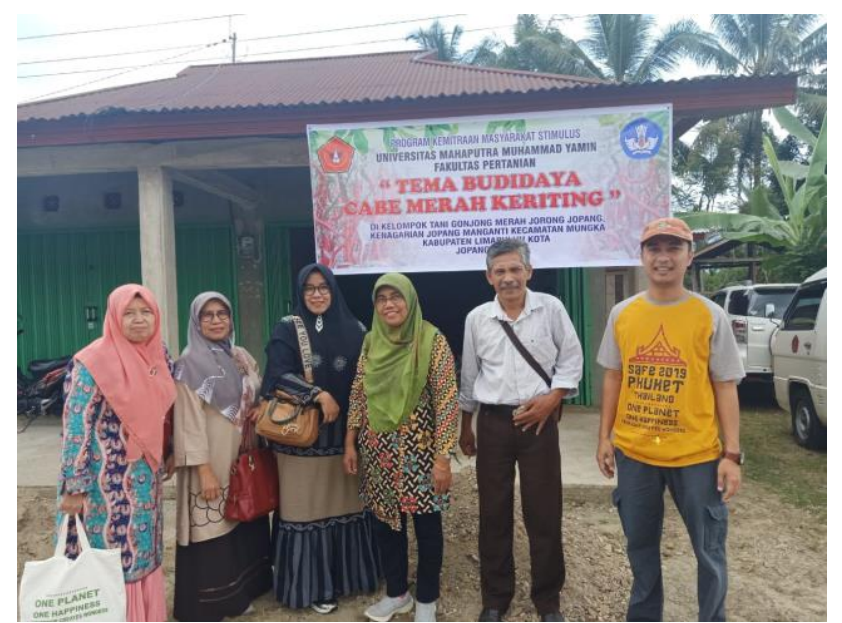

Gambar 4. Foto Bersama dengan para narasumber 


\section{SIMPULAN}

Berdasarkan dari hasil kegiatan, maka dapat disimpulkan bahwa terjadinya peningkatan pengetahuan petani mulai dari pengolahan tanah, pemupukan, penanaman, seleksi bibit cabe yang baik sampai dengan pengendalian penyakit, terjadinya peningkatan pendapatan karena terjadinya peningkatan produksi tanam.

\section{SARAN}

Agar panduan dan penyuluhan yang telah diberikan selama kegiatan PKMS tahun $2020 \mathrm{ke}$ kelompok mitra Gonjong Merah tentang budidaya cabe merah keriting varitas kencana terus di terapkan, dan terus berkomunikasi dan berdiskusi dengan pihak dan instansi terkait.

\section{UCAPAN TERIMA KASIH}

Ucapan terima kasih kepada Kementerian Riset dan Teknologi/Badan Riset dan Inovasi Nasional yang telah memberikan bantuan dana dalam kegiatan Kemitraan Masyarakat Sitimulus tahun 2020, semua tim dosen Fakultas Pertanian yang telah ikut serta membantu kegiatan ini serta masyarakat Nagari Jopang Manganti Kecamatan Mungka Kabupaten Lima Puluh Kota dima Kelompok Tani Gonjong Merah berada.

\section{DAFTAR PUSTAKA}

Dermawaan, R dan Asep Harpenas. 2010. Budidaya Cabai Unggul, Cabai Besar, Cabai Keriting, Cabai Rawit, dan Paprika. Penebar Swadaya. Jakarta.Wiwin dkk, 2007.

Nani Sumarni dan Agus Muharam. 2005. Budidaya Cabai Merah. Balai Penelitian Tanaman Sayuran.

Naniratih, I., M.B.B. Damanik, G. Sitanggang. 2013. Ketersediaan nitrogen pada tiga jenis tanah akibat pemberian tiga bahan organik dan serapannya pada tanaman jagung. J. Online Agroteknologi. 1(3): 479-488.

Rostini, N. 2011. Enam Jurus Bertanam Cabai Bebas Hama dan Penyakit. Agromedia. Jakarta. Jadwal pelaksanaan PKMS disusun dengan mengisi langsung tabel berikut dengan memperbolehkan penambahan baris sesuai banyaknya kegiatan. Daftarpustaka disusun dan ditulis berdasarkan sistem nomor sesuai dengan urutan pengutipan. Hanya pustaka yang disitasi pada usulan yang dicantumkan dalam Daftar Pustaka.

Rukmana, R., Y.Y. Oesman. 2006. Bertanam cabai dalam pot. Kanisius, Yogyakarta.

Santika, A. 2002. Agribisnis cabai. Jakarta: Penebar Swadaya. 135 hal.

Soetrisno, T.A,dan Setiawati, W. 2010. Sajian Teknis dan Ekonomis Sistem Tanam Dua Varietas Cabai Merah. J Hort.20(3):284-298.2010.

Umboh, H. A. 2002. Petunjuk penggunaan mmulsa plastik . penebar swdaya Jakarta. 